\title{
A NOTE ON TRANSLITERATION AND TRANSLATION
}

\begin{abstract}
In transliterating from the Yiddish, I have followed the YIVO system as set out in Uriel Weinreich's dictionary. Proper names were challenging, because many Polish Jews anglicized the spelling of their names, and others did not. For example, Szerer became Scherer, or Szwarc became Schwartz. In such cases, I have tried, where possible, to stick to the Anglicized versions that have appeared in the Bund's English-language materials. In other cases, people's names only appeared in Yiddish. In those instances, I have tried to follow the YIVO system.

Unless otherwise indicated, all translations from the Yiddish and French are my own.
\end{abstract}



The International Jewish

Labor Bund after 1945 
